\title{
High-resolution observations of the near-surface wind field over an isolated mountain and in a steep river canyon
}

\author{
B. W. Butler ${ }^{1}$, N. S. Wagenbrenner ${ }^{1,2}$, J. M. Forthofer ${ }^{1}$, B. K. Lamb ${ }^{2}$, K. S. Shannon ${ }^{1}$, D. Finn ${ }^{3}$, R. M. Eckman ${ }^{3}$,

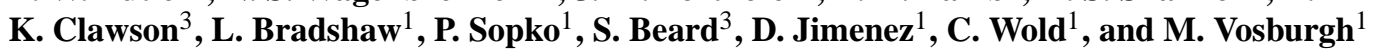 \\ ${ }^{1}$ US Forest Service, Rocky Mountain Research Station, Missoula Fire Sciences Laboratory, \\ 5775 Hwy 10 Missoula, MT 59808, USA \\ ${ }^{2}$ Washington State University, Laboratory for Atmospheric Research Pullman, WA 99164-2910, USA \\ ${ }^{3}$ NOAA Air Resources Laboratory, Field Research Division 1750 Foote Dr. Idaho Falls, ID 83402, USA
}

Correspondence to: B. W. Butler (bwbutler@fs.fed.us)

Received: 1 April 2014 - Published in Atmos. Chem. Phys. Discuss.: 25 June 2014

Revised: 23 February 2015 - Accepted: 24 February 2015 - Published: 8 April 2015

\begin{abstract}
A number of numerical wind flow models have been developed for simulating wind flow at relatively fine spatial resolutions (e.g., $\sim 100 \mathrm{~m}$ ); however, there are very limited observational data available for evaluating these high-resolution models. This study presents high-resolution surface wind data sets collected from an isolated mountain and a steep river canyon. The wind data are presented in terms of four flow regimes: upslope, afternoon, downslope, and a synoptically driven regime. There were notable differences in the data collected from the two terrain types. For example, wind speeds on the isolated mountain increased with distance upslope during upslope flow, but generally decreased with distance upslope at the river canyon site during upslope flow. In a downslope flow, wind speed did not have a consistent trend with position on the isolated mountain, but generally increased with distance upslope at the river canyon site. The highest measured speeds occurred during the passage of frontal systems on the isolated mountain. Mountaintop winds were often twice as high as wind speeds measured on the surrounding plain. The highest speeds measured in the river canyon occurred during late morning hours and were from easterly down-canyon flows, presumably associated with surface pressure gradients induced by formation of a regional thermal trough to the west and high pressure to the east. Under periods of weak synoptic forcing, surface winds tended to be decoupled from large-scale flows, and under periods of strong synoptic forcing, variability in surface winds was sufficiently large due to terrain-induced mechanical effects (speed-up over ridges and decreased speeds on
\end{abstract}

leeward sides of terrain obstacles) that a large-scale mean flow would not be representative of surface winds at most locations on or within the terrain feature. These findings suggest that traditional operational weather model (i.e., with numerical grid resolutions of around $4 \mathrm{~km}$ or larger) wind predictions are not likely to be good predictors of local nearsurface winds on sub-grid scales in complex terrain. Measurement data can be found at http://www.firemodels.org/ index.php/windninja-introduction/windninja-publications.

\section{Introduction}

Predictions of terrain-driven winds are important in regions with complex topography for a number of issues, including wildland fire behavior and spread (Sharples et al., 2012; Simpson et al., 2013), transport and dispersion of pollutants (Jiménez et al., 2006; Grell et al., 2000), simulation of convection-driven processes (Banta, 1984; Langhans et al., 2013), wind resource assessment for applications such as wind turbine siting (Chrust et al., 2013; Palma et al., 2008), wind forecasting (Forthofer et al., 2014), and climate change impacts (Daly et al., 2010). Numerous efforts have focused on improving boundary-layer flow predictions from numerical weather prediction (NWP) models by either reducing the horizontal grid size in order to resolve the effects of finer-scale topographical features on atmospheric flow (Lundquist et al., 2010; Zhong and Fast, 2003) or adding 
new parameterizations to account for unresolved terrain features (Jiménez and Dudhia, 2012).

Because NWP simulations are computationally demanding and suffer from inherent limitations of terrain-following coordinate systems in steep terrain (Lundquist et al., 2010), a number of high-resolution diagnostic wind models have also been developed to downscale wind predictions from NWP models in order to meet the needs of the aforementioned applications (e.g., Beaucage et al., 2012). However, there are limited observational data available to evaluate and improve such high-resolution models.

Fine-scale (i.e., $\sim 100 \mathrm{~m}$ ) variations in topography and vegetation substantially alter the near-surface flow field through mechanical effects, such as flow separation around obstacles, enhanced turbulence from increased surface roughness and speed-up over ridges, and through thermally driven flows induced by local differential surface heating in steep terrain (Defant, 1949; Banta, 1984; Banta and Cotton, 1982; Whiteman, 2000; Zardi and Whiteman, 2013; Chrust et al., 2013). These local-scale flow effects are critical for surface wind-sensitive processes, such as wildland fire behavior, where the near-surface wind is often the driving meteorological variable for the fire rate of spread and intensity (Rothermel, 1972; Sharples et al., 2012). In order to capture these terrain-induced effects, wind modeling in complex terrain requires that surface characteristics, including terrain, vegetation, and their interactions with the atmosphere, be resolved at a high spatial resolution.

Although diagnostic wind models do not typically employ sophisticated boundary layer schemes in their flow solutions, they often incorporate parameterized algorithms for specific boundary layer effects, such as thermally driven winds (e.g., diurnal slope flows) and non-neutral atmospheric stability (Forthofer et al., 2009; Scire et al., 2000). Evaluation of such schemes has been limited by the types of terrain features and the range of meteorological conditions represented in available observational data sets. For example, the evaluations performed by Forthofer et al. (2014) were limited by available surface wind data in complex terrain.

The two most widely used data sets for evaluation of highresolution wind predictions were collected on topographically simple, low-elevation hills investigated for wind energy applications such as the site for the Askervein Hill study (Berg et al., 2011; Taylor and Teunissen, 1987). Wind energy research has focused on relatively simple terrain because winds in complicated terrain are more difficult to forecast reliably and have higher turbulence that reduces the life of the turbines.

These studies of idealized field sites have produced useful data for investigating the effects of simple terrain obstructions on average atmospheric flow and identifying specific deficiencies in numerical flow solutions; however, such sites are not representative of the wide range of regions where terrain-induced winds occur. As a result, these data do not provide sufficient test data for evaluating spatial representa- tion of modeled flows for commonly occurring types of terrain features, such as isolated terrain obstacles with complex geometries, dissected montane environments, and steep river canyons.

Other types of observational studies, such as those designed to investigate boundary layer evolution or convectiondriven processes, have focused on characterizing the vertical distribution of wind, temperature, and moisture, but do not typically characterize the spatial variability in the near-surface wind field. Examples of the types of flow phenomenon that are of interest for high-resolution model evaluations include (1) local surface layer flow decoupling from larger-scale atmospheric flow, (2) diurnal slope flows, (3) mountain-valley flows, (4) mountain-plain flows, and (4) the interactions of these effects on multiple spatial and temporal scales.

This paper describes a research program in which wind data were collected at very high spatial resolution under a range of meteorological conditions for two different types of complex terrain features. These data sets enhance the archive of observational data available to evaluate high-resolution models. All of the data from the field program are available at https://collab.firelab.org/software/projects/wind-obs/ repository. Here we provide an overview of the data, with particular emphasis on the spatial characteristics of the surface wind measurements, and describe some unique flow features at each site. The data collected during this field campaign are used in a companion paper (Wagenbrenner et al., 2015) to evaluate near-surface wind predictions from several different NWP models and downscaling methods.

\section{Site descriptions}

\subsection{Big Southern Butte (BSB)}

BSB is a volcanic dome cinder cone approximately $4 \mathrm{~km}$ wide that rises $800 \mathrm{~m}$ above the upper Snake River Plain (USRP) in southeastern Idaho (43.3959, -113.0225) (Fig. 1). The dominant vegetation on the USRP and BSB is grass and sagebrush (generally $<1 \mathrm{~m}$ tall), although a few north-facing slopes on the butte have some isolated stands of $3-10 \mathrm{~m}$ tall conifers. Average slopes range from 30 to $40 \%$, with nearly vertical cliffs in some locations. The USRP is essentially flat terrain surrounding BSB and extends more than $120 \mathrm{~km}$ to the north, east, south, and southwest (Fig. 2). The USRP is bordered by tall mountain ranges to the northwest and southeast. There are three prominent drainages (Big Lost River, Little Lost River, and Birch Creek) that flow southeast onto the USRP nominally 20 to $80 \mathrm{~km}$ north of BSB (Fig. 2). These mountain-valley features contribute to thermally driven diurnal flows and formation of convergence zones on the USRP. Nighttime downvalley flows on the USRP are from the northeast and daytime updrainage flows are from the southwest. 

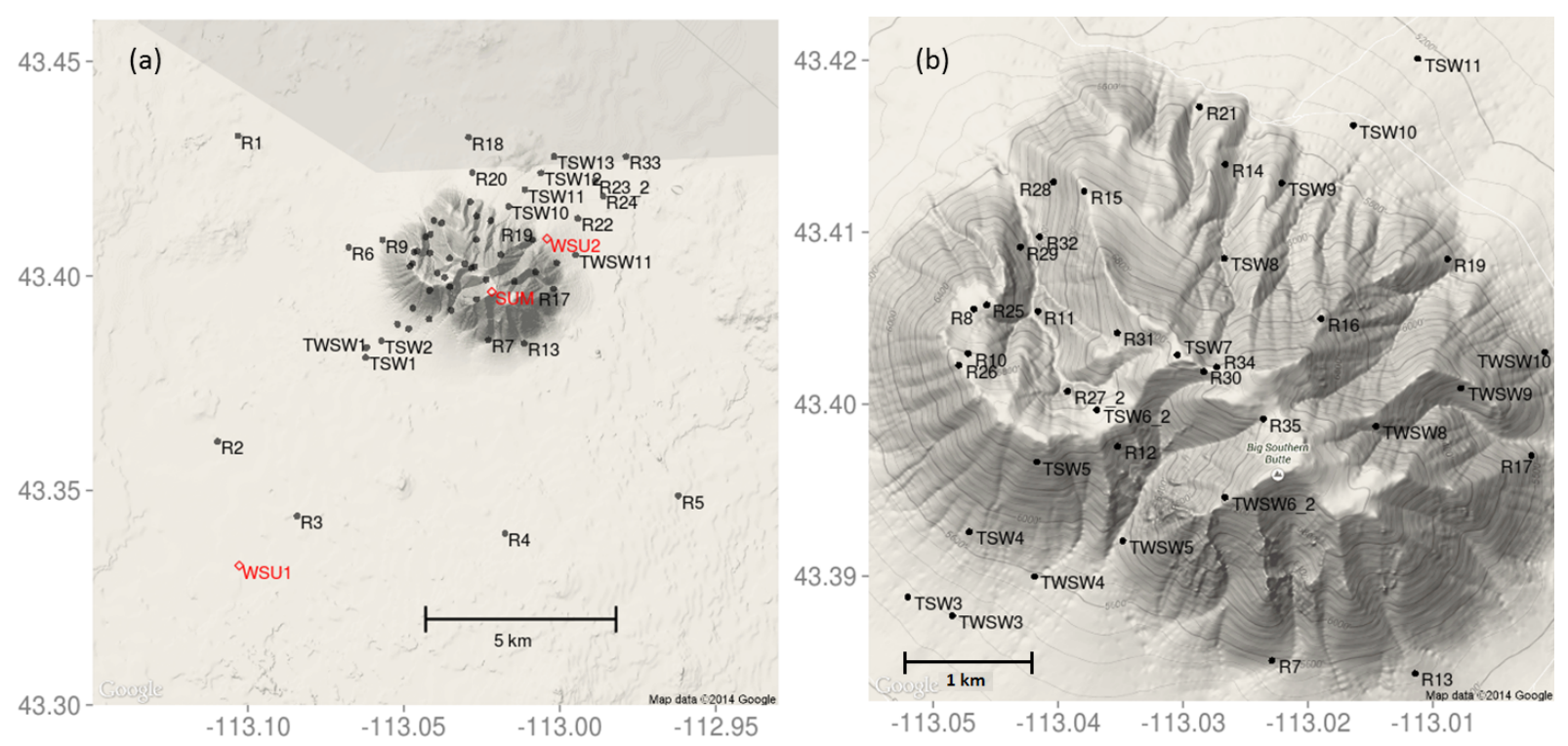

Figure 1. Sensor layout at Big Southern Butte (a) zoomed out to show the entire study area and (b) zoomed in to show sensor detail on the butte. Black circles indicate surface sensors. Red diamonds indicate sonic anemometers and vertical profiling sensors.

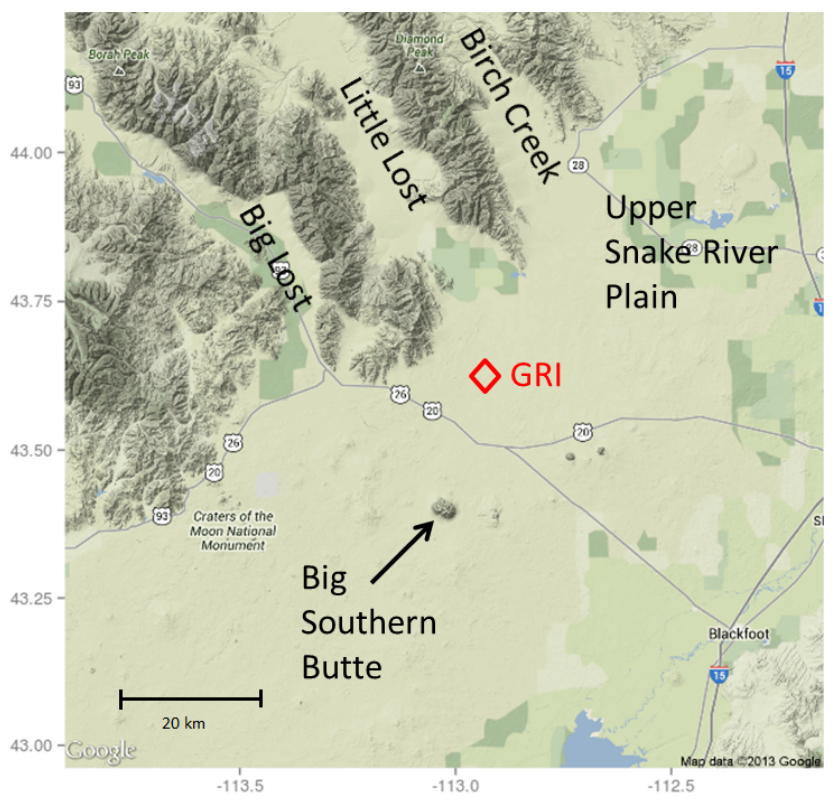

Figure 2. Snake River Plain and prominent drainages surrounding the Big Southern Butte study site. Red diamond indicates the GRI mesonet station.

Typical summertime winds on the Snake River Plain are primarily thermally driven with strong upvalley winds during the day and relatively weaker downvalley winds at night. The regional nocturnal northeasterly drainage flows usually subside by late morning, and winds begin to rotate clockwise to southwesterly flow; then, speeds increase sharply by midto-late afternoon. The strongest southwesterly wind events in the summer are associated with the passage of frontal systems.

Additionally, this region experiences occasional passage of very strong frontal systems that bring westerly winds that become channeled into southwesterly flow up the lower Snake River Plain (LSRP) toward BSB (e.g, Andretta, 2002). This same westerly synoptic flow passes over the mountains to the north of BSB and surface winds become channeled into northerly flow down the Big Lost, Little Lost, and Birch Creek drainages and onto the USRP. This northerly flow approaches BSB from the USRP, eventually converging with the southwesterly flow somewhere in the vicinity of BSB in what is referred to as the Snake River Plain convergence zone (SPCZ) (Andretta, 2002; Andretta and Hazen, 1998). When an SPCZ forms, its location shifts up or down the SRP, depending on the strength of the low-level winds over the USRP versus the LSRP (Andretta, 2002). SPCZ events most commonly occur during the winter and spring, but occasionally form during other time periods as well. Although formation of the SPCZ is not a frequent phenomenon during summer conditions, we did observe a few flow events that may have been associated with the SPCZ during our field campaign. Because the strong frontal systems that lead to formation of the SPCZ result in complicated near-surface flows on and around BSB, we investigate the observed flow events possibly associated with SPCZ-like conditions in detail in Sect. 5.1.2.

\subsection{Salmon River Canyon (SRC)}

The field site was a $5 \mathrm{~km}$ long stretch of the Salmon River Canyon located approximately $20 \mathrm{~km}$ east (upstream) of 


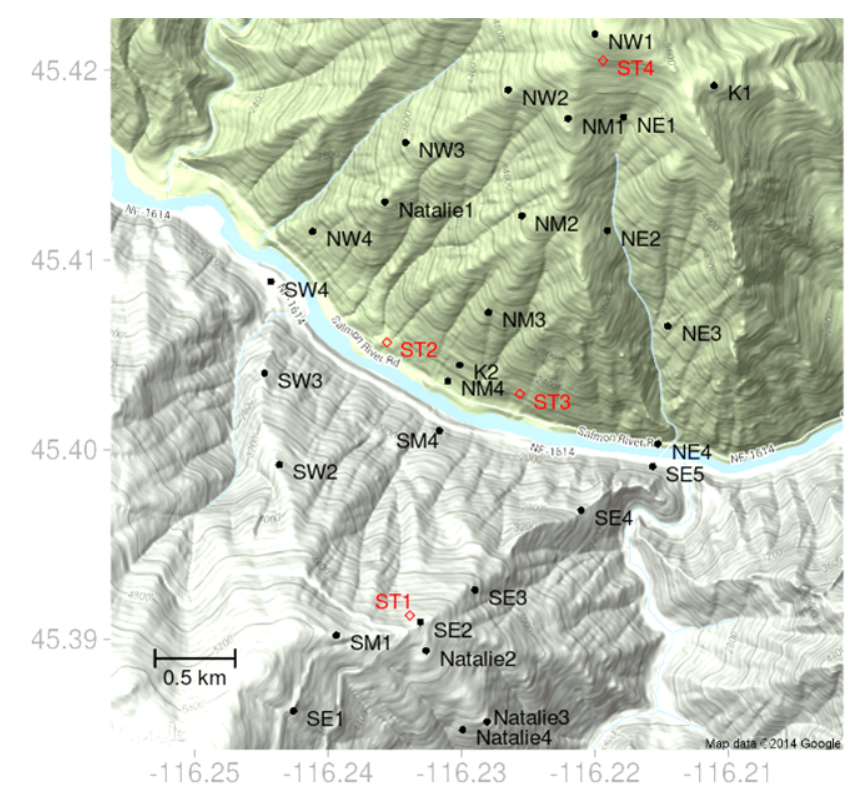

Figure 3. Sensor layout at the Salmon River Canyon. Black circles indicate surface sensors. Red diamonds indicate sonic anemometers, weather stations, and vertical profiling sensors.

Riggins, ID (45.4016, - 16.2266) (Fig. 3) and spanning in elevation from the canyon bottom $(550 \mathrm{~m})$ to the ridge tops $(1600 \mathrm{~m})$. The river canyon follows a nearly east-west path within this extent. Prevailing winds in this region are from the west. The predominant vegetation is grass (generally $<0.5 \mathrm{~m}$ tall), with some timber in the higher elevations on the northerly aspects. Our instrumentation was deployed away from forested areas, so as to avoid effects of the forest canopy on the wind flow. There were prominent side drainages entering SRC on the eastern and western ends of our study area (Fig. 3).

\section{Instrumentation}

Each field site was instrumented with a network of surface wind sensors deployed over a several month period (hereafter referred to as the monitoring period) and supplemented with short-term deployment of sonic anemometers and groundbased vertical profiling instruments. Spatially dense arrays of more than 50 cup-and-vane anemometers (S-WCA-M003, Onset Computer Corporation) measured wind speeds and directions at $3 \mathrm{~m}$ a.g.l. to characterize surface flow patterns over and within the terrain features. Wind speed and direction data were measured at $1 \mathrm{~Hz}$, and $30 \mathrm{~s}$ average wind speeds, peak gusts, and average directions were recorded. The cup and vane have a measurement range of 0 to $44 \mathrm{~m} \mathrm{~s}^{-1}$, an accuracy of $\pm 0.5 \mathrm{~m} \mathrm{~s}^{-1}$ and $\pm 5^{\circ}$, with a resolution of $0.19 \mathrm{~m} \mathrm{~s}^{-1}$ and $1.4^{\circ}$. Specific sensor locations are listed in the Supplement.

These surface measurements were complemented by sonic anemometers (CSAT3, Campbell Scientific, Inc.; SATI/3Vx,
Applied Technologies, Inc.) and vertical profiling instruments (MFAS, Scintech) at select locations and times (Table 1, Figs. 1, 3, Supplement) in order to provide measures of turbulence, friction velocity, and sensible heat flux in nearsurface flows as well as to characterize flows aloft. The Campbell Scientific CSAT3 sonic anemometers have a measurement rate of 1 to $60 \mathrm{~Hz}$, with resolutions of $1 \mathrm{~mm} \mathrm{~s}^{-1}$, $0.5 \mathrm{~mm} \mathrm{~s}^{-1}$ and $15 \mathrm{~mm} \mathrm{~s}^{-1}$ for uy, uz and c, respectively, with a direction resolution of $0.06^{\circ} \mathrm{rms}$. The SATI/3Vx has a measurement range of 0 to $20 \mathrm{~m} \mathrm{~s}^{-1}$, with a resolution of $10 \mathrm{~mm} \mathrm{~s}^{-1}$ and $0.1^{\circ}$. The Scintech MFAS samples velocities from 0 to $50 \mathrm{~m} \mathrm{~s}^{-1}$ up to $1000 \mathrm{~m}$ a.g.l. over 1 to $60 \mathrm{~min}$ averaging intervals, with horizontal wind speed uncertainty of $0.3 \mathrm{~m} \mathrm{~s}^{-1}$, vertical wind speed accuracy of $0.1 \mathrm{~m} \mathrm{~s}^{-1}$ and directional uncertainty less than $1.5^{\circ}$.

Radiosonde (iMet-1, International Met Systems), launches were conducted to characterize large-scale flows aloft for select time periods at each site. The iMet- 1 system has a maximum range of $250 \mathrm{~km}$ to an altitude of $30 \mathrm{~km}$, and measures air pressure, temperature, and humidity. Wind speed is calculated from onboard GPS measurements. Accuracy is $0.5 \mathrm{hPa}$ in pressure, $0.2^{\circ} \mathrm{C}$ in temperature, and $5 \%$ in relative humidity (RH). Wind speed is accurate to within $1 \mathrm{~m} \mathrm{~s}^{-1}$ and is updated at $1 \mathrm{~Hz}$. Altitude is accurate to within $15 \mathrm{~m}$.

Weather stations (WXT520, Vaisala) measured relative humidity, air temperature, wind speed and direction, solar radiation, and precipitation $2 \mathrm{~m}$ a.g.l. at two locations (Table 2, Fig. 3). The Vaisala WXT520 measures air temperature to $60{ }^{\circ} \mathrm{C}$ with $\pm 0.3^{\circ} \mathrm{C}$ accuracy and $0.1{ }^{\circ} \mathrm{C}$ resolution, Wind speed is measured from 0 to $60 \mathrm{~m} \mathrm{~s}^{-1}$ with $0.25 \mathrm{~s}$ response time and $\pm 3 \%$ accuracy in speed and $0.1^{\circ}$ accuracy in direction.

The sampling layouts were designed to obtain measures of the upwind approach flows as well as perturbations to the approach flow associated with the terrain features. For each site, the extent of the sensor array covered an area that spanned one to several mesoscale weather forecast grids of typical routine forecast resolution (4 to $12 \mathrm{~km}$ ) and the spatial density of the surface sensors was fine enough to resolve flow patterns on the sub-grid scale (Figs. 1 and 3). Two field sites were selected to represent an isolated terrain obstacle and a steep, non-forested river canyon. These sites provided a range of wind conditions representative of generally dry, inland, montane locations during summertime periods.

An array of 53 surface sensors was deployed on BSB between 15 June 2010 and 9 September 2010 (Fig. 1). Sensors were deployed along two transects running southwest to northeast. A number of randomly located sensors were added along and outside the two transects to increase the spatial coverage on and around the butte. A sodar profiler was deployed $2 \mathrm{~km}$ southwest of the butte from 1 July to 18 July 2010 and immediately northeast of the butte from 31 August to 1 September 2010 (Fig. 1, Table 1). A tower of sonic anemometers was deployed $2 \mathrm{~km}$ southwest of the butte from 14 July to 18 July 2010 (Fig. 1, Table 1). Three 
Table 1. Sonic anemometer and vertical profiling sensor details.

\begin{tabular}{llllll}
\hline ID & Site $^{\mathrm{a}}$ & Sensor & Model & Time period & Averaging period \\
\hline WSU1 & BSB & Sodar & Scintech & 14-15 Jul 2010 & 30 min \\
& & Sonic & ATI & 14-18 Jul 2010 & $10 \mathrm{~Hz}$ \\
\hline WSU2 & BSB & Sodar & Scintech & 15-19 Jul 2010 & $30 \mathrm{~min}$ \\
& & & 31 Aug-1 Sep 2010 & $30 \mathrm{~min}$ \\
\hline ST1 & \multirow{2}{*}{ SRC } & Weather station & Viasala, WXT & 16 Aug-12 Sep 2011 & $15 \mathrm{~min}$ \\
& & Sonic & CSAT3 & 18-19 Aug 2011 & $10 \mathrm{~Hz}$ \\
\hline ST2 & SRC & Sodar & Scintech & 16-18 Aug 2011 & $30 \mathrm{~min}$ \\
& & Sonic & ATI & 29-31 Aug 2011 & $30 \mathrm{~min}$ \\
& & & 16-18 Aug 2011 & $10 \mathrm{~Hz}$ \\
\hline ST3 & SRC & Weather station & Viasala, WXT & 17 Aug-12 Sep 2011 & $15 \mathrm{~min}$ \\
\hline ST4 & SRC & Sonic & ATI & 16-19 Aug 2011 & $10 \mathrm{~Hz}$ \\
\hline
\end{tabular}

${ }^{\mathrm{a}} \mathrm{BSB}=$ Big Southern Butte; SRC $=$ Salmon River Canyon.

Table 2. Radiosonde launches at BSB and SRC. Times are LT.

\begin{tabular}{llc}
\hline Site $^{1}$ & Date & Time of launch \\
\hline BSB & 31 August 2010 & $16: 57$ \\
& 1 September 2010 & $16: 59$ \\
& 2 September 2010 & $10: 35$ \\
SRC & 18 July 2011 & $11: 28$ \\
& & $13: 56$ \\
& & $15: 50$ \\
& & $18: 14$ \\
& & $20: 00$ \\
& & $21: 32$ \\
\hline
\end{tabular}

${ }^{1} \mathrm{BSB}=$ Big Southern Butte; $\mathrm{SRC}=$ Salmon River Canyon

radiosonde launches were conducted at BSB from 31 August to 2 September 2010 (Table 2).

An array of 27 surface sensors was deployed in three cross-river transects at SRC from 14 July to 13 September 2011 (Fig. 3). Sodars and sonic anemometers were operated from 16 July to 18 July and 29 August to 31 August 2011 (Table 1). Sodars were located in the valley bottom on the northern side of the river and at the ridge top on the northern side of the river near the eastern end of the field site (Fig. 3). Sonics were operated on northern and southern ridge tops near the western end of the study area and at two locations in the valley bottom on the northern side of the river (Fig. 1). Two weather stations monitored air temperature, relative humidity, precipitation, solar radiation, wind speed, and wind direction; one was located on the southern ridge top at the eastern end of the field site and the other was located in the valley bottom on the northern side of the river (Fig. 3). Six radiosonde launches were conducted on 18 August 2011 (Table 2).
Additionally, the National Oceanic and Atmospheric Administration Field Research Division (NOAA-FRD) operates a permanent mesonet system that consists of 35 towers spread across the USRP and encompassing the BSB study area (http://www.noaa.inel.gov/projects/INLMet/ INLMet.htm). The mesonet towers measure wind speed, wind direction, air temperature, relative humidity, and solar radiation. NOAA-FRD operates a permanent wind profiling system (915 MHz radar profiler) and radio acoustic sounding system (RASS) at a location approximately $10 \mathrm{~km}$ northeast of BSB at GRI (Fig. 2). NOAA-FRD also operated a mobile radian model 600PA sodar approximately $5 \mathrm{~km}$ south of BSB and an Atmospheric Systems Corp. (ASC) Model 4000 mini sodar $15 \mathrm{~km}$ south of BSB on 15 to 18 July 2010 and 31 August to 2 September 2010.

\section{Analysis methods and terminology}

The data analyses presented here focus on the surface wind measurements and terrain influences on the surface flow characteristics determined from these measurements. Limited data from vertical profiling instruments are provided to facilitate discussion of the surface observations. It is beyond the scope of this paper to present a comprehensive analysis of all of the data collected during these field campaigns; however, all data (surface observations, sodar, radar, radiosonde, weather station, and sonic anemometer data) are available in public archives as described in Sect. 5.3.

\subsection{Partitioning surface data into flow regimes}

The surface wind data are partitioned into four distinct wind regimes in order to facilitate the analysis of typical diurnal flows in the absence of strong synoptic forcing and high wind 
events during periods of strong synoptic forcing. The four wind regimes are

1. a downslope regime, which included downslope and downvalley flows, forced by nighttime surface cooling under weak synoptic forcing;

2. an upslope regime, which included upslope and upvalley flows, forced by daytime surface heating under weak synoptic forcing;

3. an afternoon regime, during which local flows were influenced by larger-scale flows, either through convective mixing (at BSB) or through formation of upvalley drainage winds (at SRC) under weak synoptic forcing; and

4. a synoptically forced regime, during which the normal diurnal cycle was disrupted by strong larger-scale flows typically correlated with gradient-level winds due to mechanically induced turbulent mixing in the boundary layer.

The first three are analogous to the wind regimes described in Banta and Cotton (1982) and are referred to collectively in this paper as the diurnal wind regime. The diurnal wind regime persisted during periods of weak synoptic forcing. The fourth regime was included here as the field sites investigated in this study frequently experienced periods of intense large-scale synoptic forcing that generated high surface wind speeds and sufficient mechanical mixing to overcome the diurnal flow regime.

The following procedure was used to partition the surface data into these flow regimes. First, periods during which the wind speed exceeded a threshold wind speed at a surface sensor chosen to be representative of the large-scale flow at each site were partitioned into a fourth, synoptically forced, regime (4). Threshold wind speeds were selected for each site based on visual inspection of the wind speed time series data for the chosen sensors. Thresholds were selected to be speeds that were just above the typical daily peak speed for the chosen sensors. In other words, the threshold speed was only exceeded when synoptic forcing disrupted the typical diurnal wind regime at a given site. Speeds below the threshold are indicative of periods of weak synoptic forcing, during which the diurnal wind regime prevails.

Sensors R2 and NM1 were chosen to be the representative sensors at BSB and SRC, respectively. R2 was located on the USRP approximately $5 \mathrm{~km}$ southwest of the butte. NM1 was located on the northern side of the SRC at $1530 \mathrm{~m}$ a.s.l., roughly three-quarters of the distance from the canyon bottom to the ridge top. These sensors were chosen because they appeared to be the least influenced by the terrain and most representative of the gradient-level winds. Threshold velocities of 6 and $5 \mathrm{~m} \mathrm{~s}^{-1}$ were chosen for BSB and SRC, respectively (Fig. 4). 83 and $80 \%$ of the data fell below these

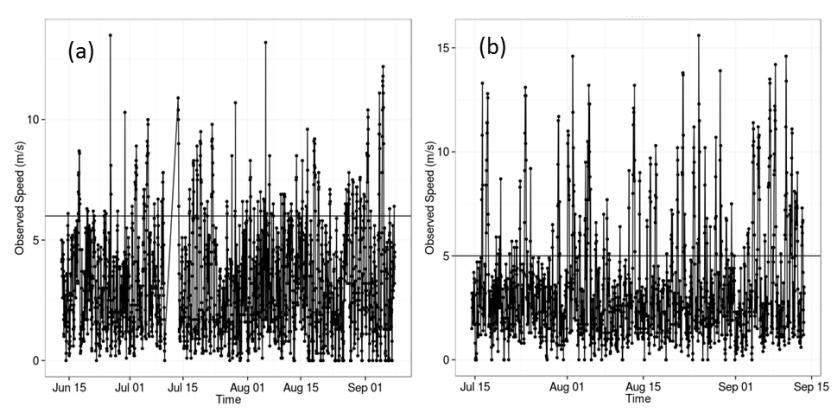

Figure 4. Observed hourly wind speeds for (a) sensor R2 at Big Southern Butte and (b) NM1 at the Salmon River Canyon study site. The horizontal line indicates the threshold speed chosen to partition synoptically driven events from diurnal events.

threshold speeds at BSB and SRC, respectively. Speeds below these thresholds fall within the range of diurnal wind flows reported in the literature (Horst and Doran, 1986) and visual inspection of the vector maps further confirmed this choice of threshold wind speeds, as all four regimes were clearly identified by the surface flow patterns at each site.

After filtering out the synoptically driven periods, the remaining data were then partitioned into regimes (1-3) based on visual inspection of the hourly vector maps. Periods that exhibited clearly defined downslope flow were partitioned into regime (1). Periods that exhibited clearly defined upslope flow were partitioned into regime (2). And afternoon periods during which the upslope regime was disturbed were partitioned into regime (3). Transition periods from one regime to another were also identified based on visual inspection of the hourly vector maps.

We used INL Mesonet data at the summit of BSB (Fig. 1, "SUM") as well as archived North American Mesoscale Model (NAM) forecasts as indicators of upper-level flows for comparison with our surface measurements. References in the text to upper-level or gradient-level winds refer to flows observed in these data sources.

\subsection{Data averaging}

Surface wind observations were averaged over a $10 \mathrm{~min}$ period at the top of each hour to represent an average speed valid at the top of each hour. This averaging scheme was chosen to be representative of wind speeds from NWP forecasts. Although NWP output is valid at a particular instant in time, there is some inherent averaging in these "instantaneous" predictions. The averaging associated with a given prediction depends on the time step and grid spacing used in the NWP model, but is typically on the order of minutes. The 10 min averages are referred to in the text as "hourly" data.

Hourly vector maps were used to visualize the spatial patterns of the wind fields for classifying flow regimes. The vector maps were produced by partitioning the hourly data into one of two categories, (1) strong synoptic forcing or 
(2) weak synoptic forcing (i.e., diurnal winds dominate), and then by averaging the hourly data (for each sensor) within each category over the entire monitoring period. The result is an hourly average wind vector at each sensor location for each flow category. For example, a vector map for 13:00 under weak synoptic forcing would be produced by filtering out the periods of strong synoptic forcing and then averaging all hourly flow data for 13:00 at each sensor over the entire monitoring period. Partitioning of data into weak versus strong synoptic forcing was described in Sect. 4.1.

All data analysis and visualization was performed in $\mathrm{R}$ (R Core Team, 2013). Vector maps were produced using the ggmap library (Kahle and Wickam, 2013) and diurnal wind contour plots were produced using the metvurst library (Salabim, 2013).

\section{Results and discussion}

Results for BSB are presented in Sect. 5.1. Results for SRC are presented in Sect. 5.2. Average flows for the diurnal wind regimes are presented for each site and then the disturbance to the diurnal wind regime by synoptic-scale forcing is described. Transitions within the diurnal wind regime (e.g., upslope to afternoon regime) occurred at roughly the same time of day throughout the monitoring periods, with no discernible differences between average hourly vector maps for the first and second halves of the monitoring period. Thus, results for diurnal winds are reported as averages for the entire monitoring period. This is reasonable since monitoring periods were during summertime conditions at both sites. All times are reported as local daylight time.

\subsection{BSB}

\subsubsection{Diurnal winds: upslope, afternoon, and downslope regimes}

Diurnal slope winds are driven by solar-induced horizontal temperature gradients between the ground surface and the air. Whiteman (2000) provides a thorough discussion of diurnal mountain winds. The diurnal wind regime for an isolated mountain is typically characterized by upslope winds during the day due to local solar heating of the surface and downslope winds at night due to local surface cooling. An afternoon, or coupled, regime often develops when gradientlevel winds become mixed in with the growing surface layer. There is a transition phase between each phase of the diurnal cycle as the temperature structure of the atmosphere responds and adjusts to the changing incident solar radiation at the surface. The daily cycle can be disturbed by interference from larger-scale winds.

Sunrise ranged from 06:00 to 07:00 LT during the monitoring period. Upslope winds formed between 08:00 and 09:00 and the upslope regime was fully established by 10:00 and persisted until around 12:00. Upslope winds peaked around
11:00. This regime was characterized by thermally driven upslope winds on all sides of the butte flowing up from the surrounding SRP (Fig. 5a). Vertical profiles measured at GRI indicated fairly well-mixed upvalley flow by 11:00 LT, with a slightly positive w-component to the flow up to $50 \mathrm{~m}$ a.g.l. (Fig. $6 \mathrm{~b}$ ).

The timing of onset and occurrence of peak winds in the upslope regime was consistent with Banta and Cotton (1982) and Geerts et al. (2008), who reported peaks in upslope flow before local solar noon (LSN) for relatively small mountains. Others have reported later peaks in upslope flow after LSN for larger mountain ranges (McNider and Pielke, 1981; Reiter and Tang, 1984). Geerts et al. (2008) discussed this discrepancy in the reported timing of upslope flows for different mountain ranges and described the development of upslope winds as scaling with the size of the mountain. BSB is a relatively small isolated mountain by the Geerts et al. (2008) terminology: a horizontal scale of $\sim 5 \mathrm{~km}$ and a vertical scale of $\sim 800 \mathrm{~m}$ above the surrounding SRP and, so, establishment of the upslope regime prior to LSN fits with this scaling theory. Upslope flows persisted about $2 \mathrm{~h}$ longer than those at the South Park site in Colorado reported by Banta and Cotton (1982). This difference could be attributed to the upwind terrain, as westerly flows from the Rocky Mountains at the South Park site were likely more turbulent than the southwesterly flows approaching BSB from the SRP, and perhaps were able to more quickly entrain the developing convective boundary layer (CBL) at South Park.

Wind speeds in the upslope regime ranged from 1.8 to $7.3 \mathrm{~m} \mathrm{~s}^{-1}$, with an average of $3.1 \mathrm{~m} \mathrm{~s}^{-1}$ (Table 3). There were a few ridgetop sensors that appeared to be decoupled from the diurnal flow regime on the butte (discussed in detail at the end of this section); if these sensors are removed, the wind speeds ranged from 1.8 to $4.5 \mathrm{~m} \mathrm{~s}^{-1}$, with an average of $3.0 \mathrm{~m} \mathrm{~s}^{-1}$. These are higher speeds than those reported by Geerts et al. (2008) but similar to the range reported by Banta and Cotton (1982). Differences in the reported range of speeds between this study and Geerts et al. (2008) could be attributed to differences in the actual quantities reported. Geerts et al. (2008) used an averaging scheme to calculate a mean anabatic wind that is a function of the circumference of the polygon obtained by connecting the midpoints between observation stations around the mountain. Also, their wind measurements were made at $10 \mathrm{ma}$ a.g.l., while ours were made at $3 \mathrm{~m}$ a.g.l. Upslope wind speeds were typically higher further up the slopes than lower on the butte (Figs. 7a, 8). Ridgetop sensors also appeared to be less coupled with the diurnal flow regime on the butte and more correlated with the large-scale flows; this is confirmed by contour plots of wind direction over time (Fig. 8) and is discussed in further detail at the end of this section.

Upslope winds transitioned to the afternoon regime between 12:00 and 13:00. This transition is most notable by an increase in wind speeds on the southwestern side of the butte and a shift in the wind directions on the northeastern 


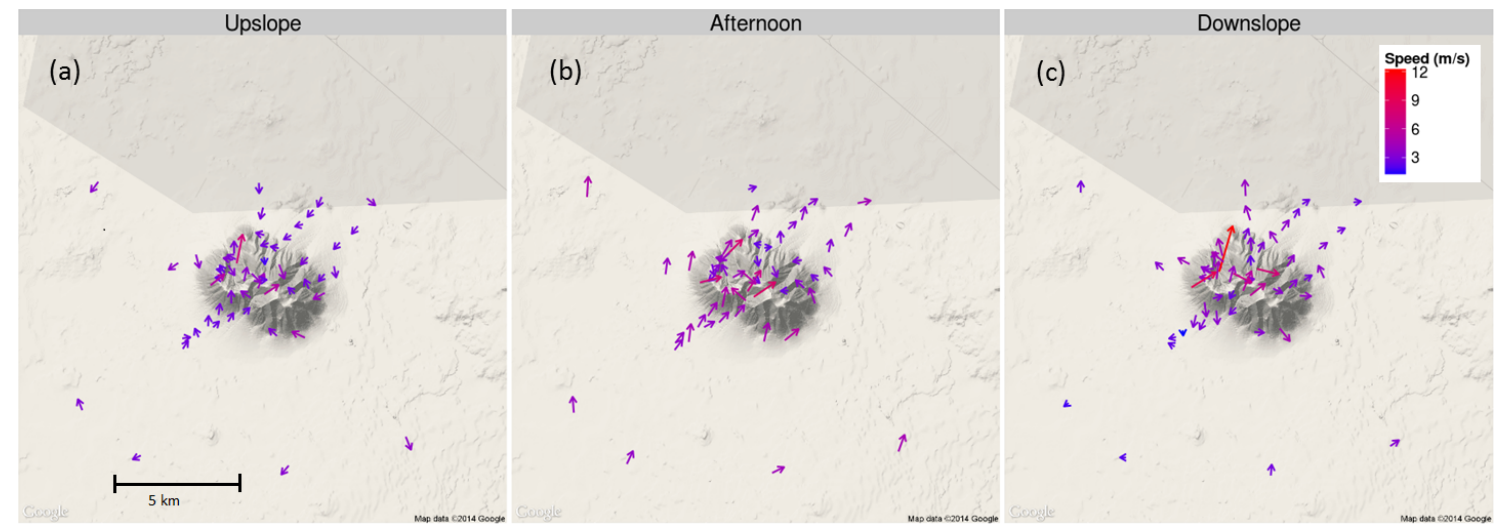

Figure 5. Average flow during (a) upslope (11:00 LT), (b) afternoon (16:00 LT), and (c) downslope (00:00 LT) flow regimes at Big Southern Butte during periods of weak synoptic flow between June and September 2010. Vectors represent the average hourly flow at a given sensor. Vectors are centered on sensor locations. Periods of strong synoptic forcing were removed prior to averaging.

Table 3. Measured wind speeds $\left(\mathrm{m} \mathrm{s}^{-1}\right)$ during upslope, downslope, and convective mixing regimes at Big Southern Butte (BSB) and Salmon River Canyon (SRC). Decoupled ridgetop locations (sensors R26, R35, TSW7, and R15) were omitted from BSB averages; speeds in parentheses include ridgetop sensors. Times are local.

\begin{tabular}{lllll}
\hline Site & Wind speed & Upslope (11:00) & Afternoon (16:00) & Downslope (00:00) \\
\hline \multirow{2}{*}{ BSB } & Min $\left(\mathrm{m} \mathrm{s}^{-1}\right)$ & 1.8 & 2.3 & 1.3 \\
& Max $\left(\mathrm{m} \mathrm{s}^{-1}\right)$ & $4.5(7.3)$ & 8.1 & $7.5(12.0)$ \\
& Mean $\left(\mathrm{m} \mathrm{s}^{-1}\right)$ & $3.0(3.1)$ & 4.1 & $3.4(3.7)$ \\
\hline \multirow{2}{*}{ SRC } & Min $\left(\mathrm{m} \mathrm{s}^{-1}\right)$ & 0.75 & 0.92 & 0.33 \\
& Max $\left(\mathrm{m} \mathrm{s}^{-1}\right)$ & 4.0 & 4.2 & 4.1 \\
& Mean $\left(\mathrm{m} \mathrm{s}^{-1}\right)$ & 2.4 & 2.5 & 1.2 \\
\hline
\end{tabular}

side of the butte (Fig. 5b). This regime included local flows that generally correlated with the gradient-level winds above the ridge tops due to convective mixing in the deep afternoon boundary layer. Convective mixing was fully established by 14:00 and persisted until around 20:00. Wind speeds peaked around 15:00 and were fairly consistent through 19:00. Vertical profiles confirmed well-mixed southwesterly flow with little vertical motion during afternoon flow conditions at GRI (Fig. 6c).

The onset of the afternoon regime was slightly later in the day than that reported by Banta and Cotton (1982), which could be due to less turbulent approach flow at BSB as discussed above. During the afternoon regime, the prevailing southwesterly flow was routed around the northwestern and southeastern sides of the butte (e.g., sensors R9 and R13). Wind speeds were highest on the ridge tops and southwestern slopes and lowest on the northeastern slopes (Fig. 5b). There was some apparent recirculation on the northeastern side of the butte as well as in some of the side drainages (Fig. 5b). Wind speeds in the afternoon regime ranged from $2.3 \mathrm{~m} \mathrm{~s}^{-1}$ to $8.1 \mathrm{~m} \mathrm{~s}^{-1}$, with an average of $4.1 \mathrm{~m} \mathrm{~s}^{-1}$.

Sunset ranged from 20:30 to 21:30 during the monitoring period. The afternoon regime began to decay and transition into downslope winds between 21:00 and 22:00. The downslope regime was fully established by 23:00 and persisted until around 08:00. Peak downslope winds occurred around 00:00. The timing of onset and the occurrence of peak winds in the downslope regime agreed with observations reported in Banta and Cotton (1982). Downslope flows are clearly shown in the hourly vector plots, with flows going from the top of the butte down all side drainages around the butte and flowing out onto the SRP (Fig. 5c). Vertical profiles measured at GRI showed downvalley flow at heights up to $100 \mathrm{~m}$ a.g.l. on the SRP by 00:00 (Fig. 6a). Wind speeds in the downslope regime ranged from 1.3 to $12.0 \mathrm{~m} \mathrm{~s}^{-1}$, with an average of $3.7 \mathrm{~m} \mathrm{~s}^{-1}$. If the decoupled ridgetop sensors are removed, the range was 1.3 to $7.5 \mathrm{~m} \mathrm{~s}^{-1}$, with an average of $3.4 \mathrm{~m} \mathrm{~s}^{-1}$ (Table 3). This range is similar to that reported in Banta and Cotton (1982) and slightly larger than that reported in Horst and Doran (1986). Others have proposed an acceleration of flow with downslope distance due to thickening of the katabatic layer from entrainment of ambient air into the slope flow and increased buoyancy deficit with downslope distance (Horst and Doran, 1986); however, we did not observe a consistent trend in wind speed with location on the slope (low versus high) during the downslope regime (Fig. 7b). 


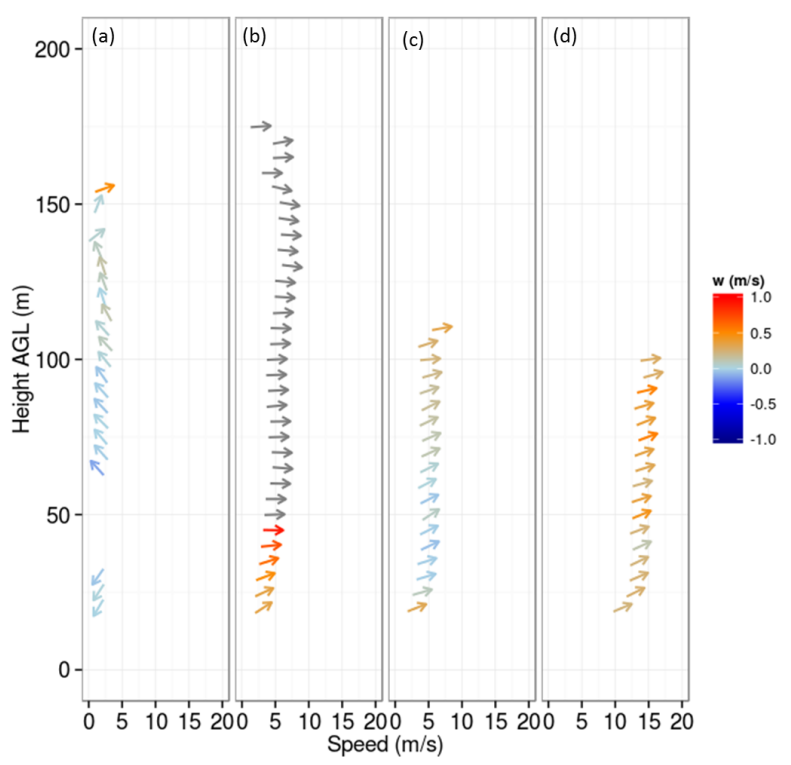

Figure 6. Vertical profiles measured at GRI duirng (a) downslope (14 July 2010, 00:00 LT), (b) upslope (15 July 2010, 11:00 LT), (c) afternoon (15 July 2010, 16:00 LT), and (d) synoptically forced (17 July 2010, 15:00 LT) flow regimes.

Diurnal winds dominated the local flows on and around the butte under periods of weak synoptic forcing. During these periods, flow on and around BSB was decoupled from the large-scale atmospheric flows, except for high-elevation ridgetop sensors (R26, R35, TSW7) and one exposed midelevation ridge sensor (R15). This decoupling is evident from the vector maps (Fig. 5) and is also confirmed by the contour plots that show that these ridgetop locations do not experience the strong diurnal shifts in wind direction that other locations on and around the butte experience (Figs. 8, 9).

This ridgetop decoupling likely occurred because these locations were high enough in the atmosphere to protrude out of the nocturnal boundary layer (NBL) and because of the morning time developing shallow CBL. Thus, the ridgetop winds were coupled with the large-scale flows during all periods of the day. During nighttime hours, the ridgetop locations would experience residual layer winds and would only be coupled with the rest of the flow on and around the butte once the residual layer was entrained by the growing shallow CBL and the convective mixing regime was fully established. This proposed structure is supported by the vector plots, which show that ridgetop winds did not change much from one regime to the next and only correlated with winds at other nearby locations on the butte during the convective mixing regime (Fig. 5). The vertical profile measured at GRI at 00:00 shows downvalley flow up to about $100 \mathrm{~m}$ a.g.l. and upvalley flow above this height (Fig. 6a); this further supports the idea that ridgetop locations (i.e., heights up to $800 \mathrm{~m}$ a.g.l. on the SRP) could have been exposed to residual layer winds during nighttime flows, and thus are more correlated with gradientlevel winds than surface flows at other locations on the butte.

\subsubsection{Synoptic disturbance of diurnal winds}

Under periods of strong synoptic forcing, such as the passage of a cold front, the diurnal wind regime was disrupted and a synoptically forced regime persisted. Two types of flow events occurred within the synoptically forced regime, one with southwesterly flow and one with northeasterly flow (Fig. 10). The diurnal slope flows on BSB were completely overtaken by the larger-scale flows in this regime (Fig. 10 vs. Fig. 5). During these events, daytime winds were consistently from the southwest, but in a few cases, during nighttime and early morning hours, winds were from the northeast (Fig. 10). Fig. 6d shows the vertical profile of winds measured at GRI during a synoptically forced southwesterly flow event.

The southwesterly flows are referred to as "synoptically driven upvalley" flows and the northeasterly flows are referred to as "synoptically driven downvalley" flows. Synoptically driven upvalley flows were generally associated with the passage of cold fronts from the west/southwest. Evolution of the synoptically driven downvalley flows is more complex and some potential mechanisms are described below. Wind speeds during the synoptically driven upvalley flows ranged from 2.9 to $20.3 \mathrm{~m} \mathrm{~s}^{-1}$, with an average of $7.1 \mathrm{~m} \mathrm{~s}^{-1}$; the downvalley flow speeds ranged from 0.1 to $24.4 \mathrm{~m} \mathrm{~s}^{-1}$, with an average of $6.0 \mathrm{~m} \mathrm{~s}^{-1}$. The synoptically driven downvalley (northeasterly) flows occurred less frequently than the synoptically driven upvalley (southwesterly) flow events; however, four distinct nighttime northeasterly flow events were observed during the monitoring period.

There are at least three potential mechanisms that may have contributed to the synoptically driven downvalley events that we observed. One mechanism is related to the SPCZ described in Sect. 2.1. Mechanical channeling of the gradient-level winds by the surrounding terrain to the north and strong southwesterly flows on the SRP can create an SPCZ-like convergence zone with strong upvalley winds to the south of the zone and strong downvalley winds to the north of the zone. Winds at BSB could be southwesterly or northeasterly, depending on which side of the convergence zone it was on. A second mechanism is based on observations from the NOAA mesonet, suggesting that, during summer months, SPCZ-like events occur in association with the passage of fronts or thunderstorm activity in the mountains to the north. The former will often generate strong outflows through the northern valleys onto the SRP, and the latter will sometimes generate outflow gust fronts. A third possibility is that surface pressure gradients, in some cases, may have contributed to the northeasterly flows. Two of the observed synoptically driven downvalley flow events occurred during periods where there was a strong northeasterly to southwesterly surface pressure gradient that could have facilitated the 

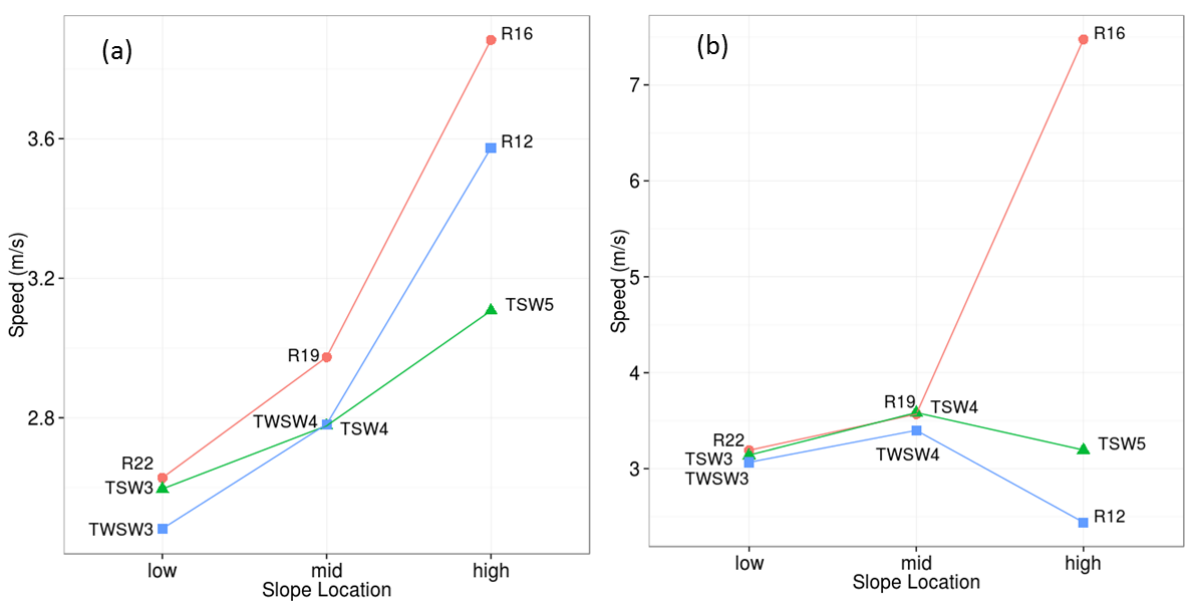

Figure 7. Average wind speeds for sensors at three slope locations (low, mid, and high) along three transects during the (a) upslope (11:00 LT) and (b) downslope (00:00 LT) flow regimes at Big Southern Butte.
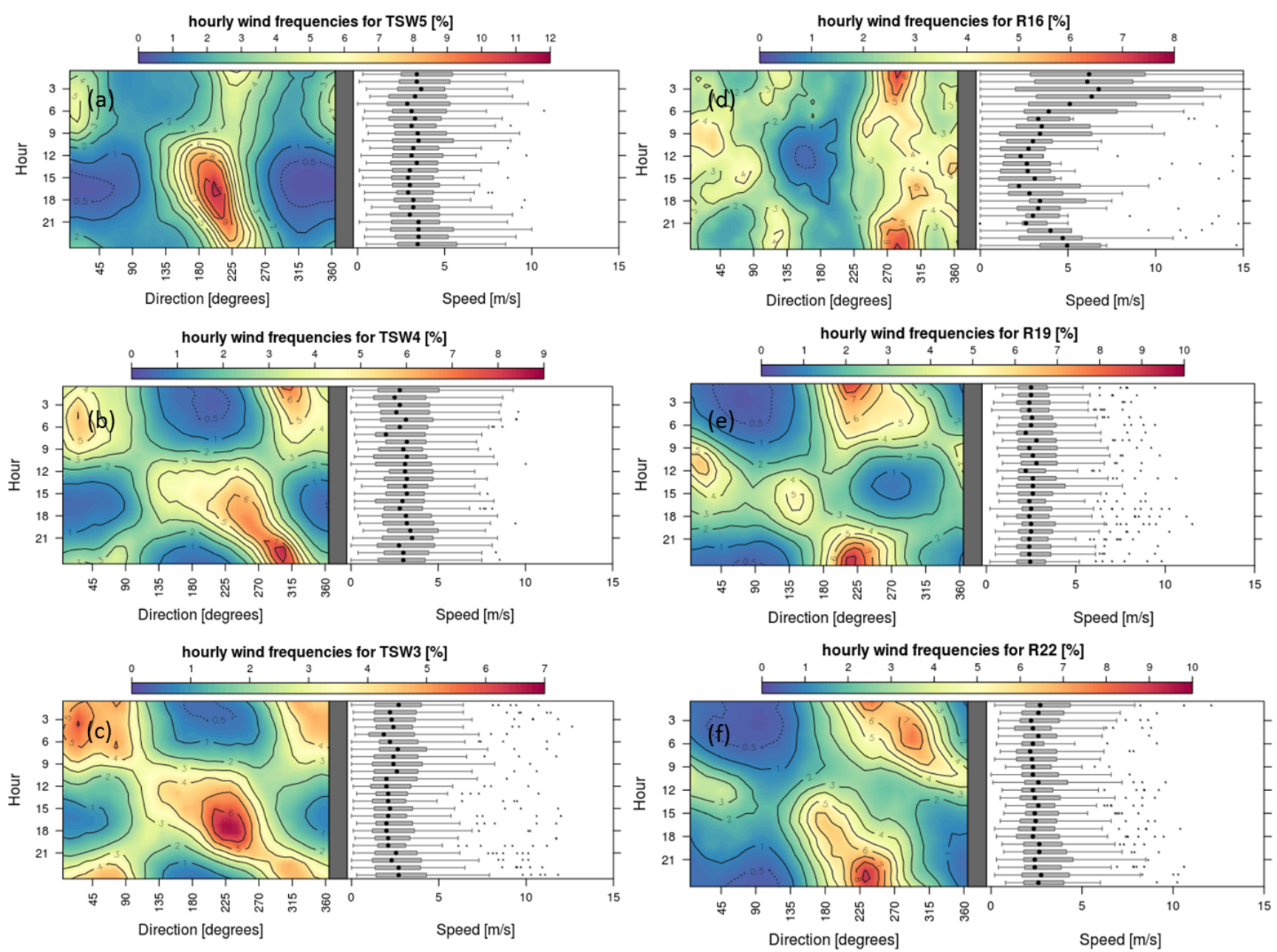

Figure 8. Contour plots of hourly wind frequencies and corresponding wind speeds for a transect on the southwestern slope of Big Southern Butte (a-c) and a transect on the northeastern slope of Big Southern Butte (d-f). Panels are ordered from higher-elevation sensors (a, d) to lower-elevation sensors $(\mathbf{c}, \mathbf{f})$. Periods of synoptic forcing were removed from these data. 
flow; however, the other two observed synoptically driven downvalley events did not occur during periods of favorable surface pressure gradients, so although surface pressure may be an influence, it was not the sole cause of these strong downvalley flow events. It is possible that any combination of these three mechanisms may have contributed to the observed downvalley flows on BSB.

It is interesting that, during periods of synoptically driven downvalley flows, wind speeds were generally higher on the southwestern (leeward) side of BSB than on the northeastern (windward) side. Perhaps this is because the maximum in the synoptically driven downvalley flow occurred at some higher elevation and was not well mixed with near-surface winds due to nighttime temperature stratification in the NBL. This stratified flow could have become mixed into the surface flow at the ridge tops and pulled down the southwestern side of BSB. The northeasterly flow also would have been enhanced by the nighttime downslope flow on the southwestern side of $\mathrm{BSB}$, thus producing stronger winds on this side as compared to the northeastern (windward) side, where the downslope flow would be in opposition (southwesterly) to the northeasterly flow.

\subsection{SRC}

\subsubsection{Diurnal winds: upslope, afternoon, and downslope regimes}

The diurnal wind regime for a canyon or valley is similar to that of the isolated mountain, with upslope/upvalley winds during the day due to local solar heating of the surface and downslope/downvalley winds at night due to local surface cooling. However, the afternoon, or coupled, regime often does not develop in deep or narrow canyons due to strong atmospheric decoupling of the canyon flows from the upperlevel winds (Banta and Cotton, 1982).

Sunrise ranged from 05:00 to 06:30 during the monitoring period at SRC. Upslope winds formed around 09:00 and were fully established by 10:00, peaked around 12:00 and persisted until around 15:00. The upslope regime was characterized by thermally driven upslope winds on both sides of the canyon as well as up smaller side drainage slopes (Fig. 11a). The one notable exception was sensor NM2, which experienced easterly or southeasterly flow during most periods of the day (Fig. 11). We believe this sensor was perhaps located in a local recirculation zone formed in the small side drainage; this is discussed at the end of this section. Wind speeds in the upslope regime ranged from 0.75 to $4.0 \mathrm{~m} \mathrm{~s}^{-1}$, with an average of $2.4 \mathrm{~m} \mathrm{~s}^{-1}$ (Table 3). Vertical profiles measured at ST2 indicated a transition from downvalley to upvalley flow beginning near the surface and propagating upward to $100 \mathrm{~m}$ a.g.l. by 09:30 (Fig. 12c).

Wind speeds tended to be highest at the upper-elevation sensors around the onset of the upslope regime at 09:00 (Fig. 13a). As the upslope regime developed, wind speeds peaked around 11:00 and were highest at the mid-elevation sensors (Fig. 13) and this trend continued through 13:00. The northwesterly and southeasterly transects do not follow these trends. The northwesterly transect had consistently lower speeds at the mid-elevation sensor during all periods of the upslope regime. This could be because NW3 was located slightly off the ridge on a northwesterly aspect and perhaps decoupled from the flow along the rest of the northwesterly transect. The southeasterly transect had consistently higher speeds at the mid-elevation sensor (SE4). The higher speeds at SE4 could be because this sensor was located on a ridge exposed to a prominent side drainage (Lake Creek) just to the east of the study area (Fig. 3). Flows out of this Lake Creek drainage could have influenced this sensor more than others along the SE transect due to its location on the ridge and steep terrain to the southeast (Fig. 3).

We did not observe afternoon convective mixing at SRC as we did at BSB. This is consistent with Banta and Cotton (1982), who noted that a true convective mixing regime is not well documented in narrow mountain canyons, likely due to the strong channeling effect exerted by the canyon on the flow. The afternoon regime at SRC was characterized by a change from upslope to upvalley winds around 15:00. This afternoon upvalley regime was fully established by 16:00 and persisted through 19:00. The most notable change between the upslope regime and the afternoon regime was the shift in wind direction from up the canyon walls (northerly or southerly flow) to upriver (westerly flow), especially for the lower-elevation sensors. Daytime gradient-level winds were typically from the west (upriver winds), so it could be difficult to determine if this afternoon shift in wind direction was driven by convective mixing of gradient-level winds down into the canyon or the formation of thermally driven upvalley flow within the canyon. The fact that this change in wind direction was most notable in the lower-elevation sensors (Fig. 11) points to a thermally driven mechanism. Wind speeds were fairly consistent throughout this time period and ranged from 0.92 to $4.2 \mathrm{~m} \mathrm{~s}^{-1}$, with an average of $2.5 \mathrm{~m} \mathrm{~s}^{-1}$ (Table 3). Wind speeds were the lowest near the canyon bottom, except for the southeasterly and northwesterly transects, which had the lowest speeds at high- and mid-elevation sensors (Fig. 14). Both of these sensors were located slightly off of the main ridge. It is interesting that the lowest sensors responded most noticeably to the shift from upslope to upvalley flow with a change in wind direction, but that the highest speeds were still observed at the upper-elevation sensors.

Sunset ranged from 19:00 to 20:30 during the monitoring period. Upvalley flow began to weaken and transition to downslope flow between 20:00 and 21:00. The downslope regime was fully established by 22:00 and persisted until around 07:00. Vertical profiles of wind speeds measured at ST2 indicated a transition to downvalley flow by 20:00 (Fig. 12a). Peak wind speeds in the downslope regime occurred around 22:00. Wind speeds in the downslope flow regime ranged from 0.33 to $4.1 \mathrm{~m} \mathrm{~s}^{-1}$, with an average of 

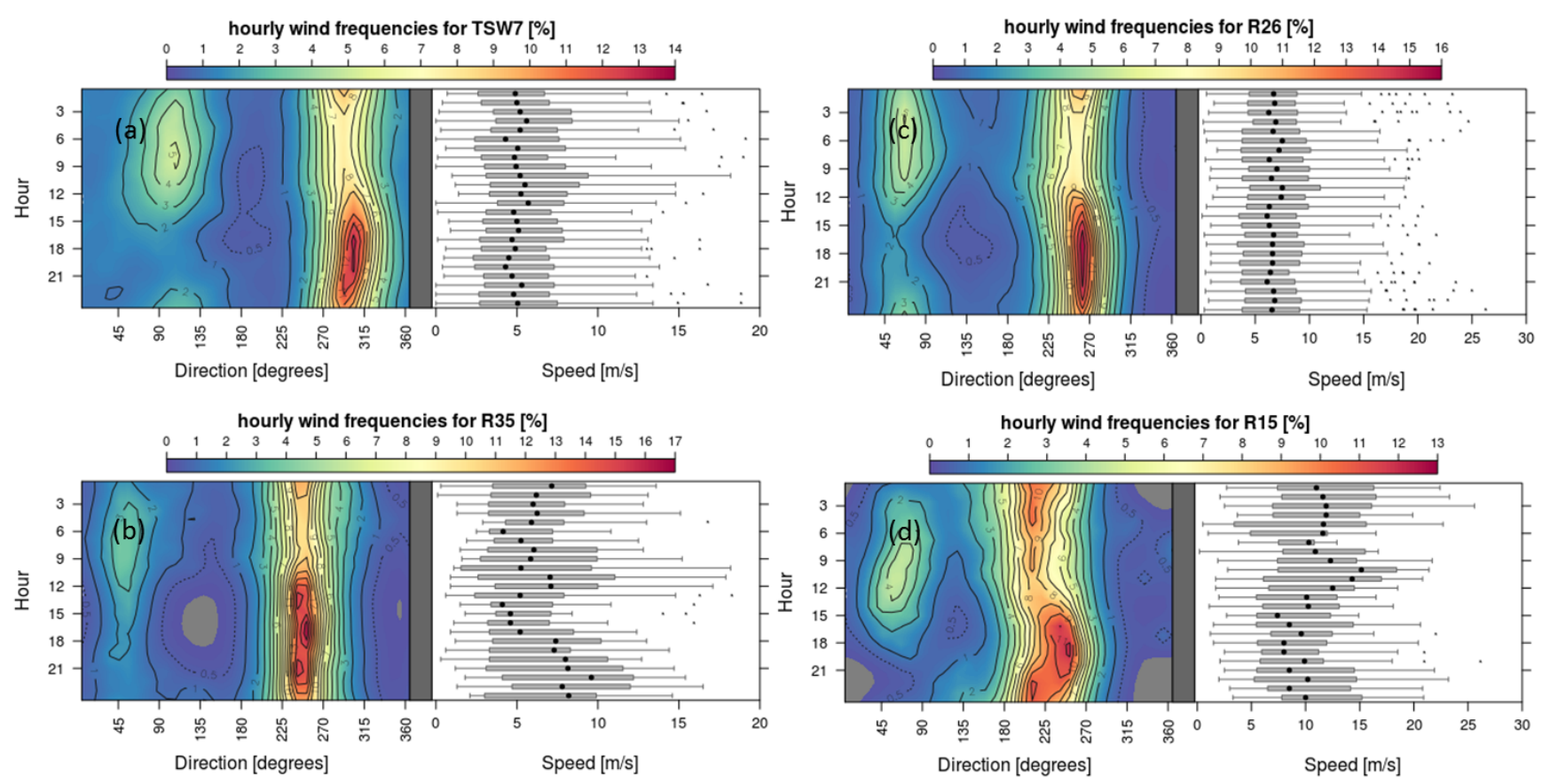

Figure 9. Contour plots of hourly wind frequencies and corresponding wind speeds for four ridgetop locations at Big Southern Butte. Periods of strong synoptic forcing were removed from these data.

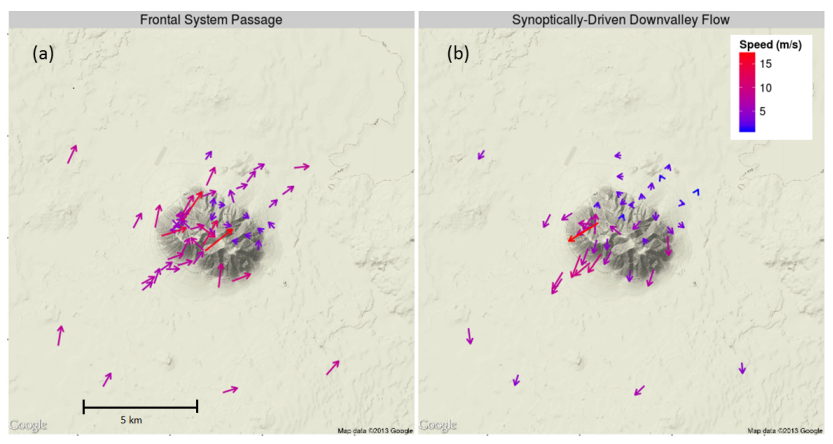

Figure 10. Characteristic synoptically driven regime events during (a) the passage of a frontal system (18:00 LT) and (b) during synoptically enhanced downvalley flow on the Snake River Plain (23:00 LT) at Big Southern Butte during June-September 2010. Vectors represent the average hourly flow at a given sensor. Periods of weak synoptic forcing were removed prior to averaging. The lower strip is zoomed out to show the entire study area.

$1.2 \mathrm{~m} \mathrm{~s}^{-1}$ (Table 3). Wind speeds tended to increase with upslope distance (Fig. 13d-f), with the exception of the SE transect, likely due to the location of SE3 and SE4 as discussed above. This trend was consistent throughout the duration of the downslope regime.

Diurnal trends were further inspected for the NM transect because it was not located near any prominent side drainages and likely exhibited the simplest flow characteristics. Contour plots show a strong diurnal signal for all sensors in this transect (Fig. 15), indicating that diurnal flows are a major flow feature in the SRC. Winds were from the east/southeast in the early morning and from the west/northwest in the afternoon, and the highest speeds occurred at the upperelevation sensors during early morning hours. One exception was the NM2 sensor, which rarely experienced winds from the west/northwest and did not experience a morning time peak in wind speed. This sensor was located slightly off of a mid-slope ridge on a slope with a northwesterly aspect. We suspect that this location was possibly a zone of recirculation. The lowest sensor, NM4, also did not experience a morning peak in wind speed and rarely experienced winds from the northeast. The highest speeds occurred during periods of synoptic disturbance, which we believe had more of an effect at upper elevations in the SRC than lower ones near the river bottom. This is discussed further in the next section.

\subsubsection{Synoptic disturbance of diurnal winds}

Two types of synoptic disturbances to the diurnal wind regime in the SRC were observed (Fig. 16). One is associated with the passage of frontal systems from the west, which brings strong westerly gradient winds. The other appears to be associated with the presence of an east-west pressure gradient that generates strong morning-time easterly flow. During the passage of frontal systems, westerly winds are channeled up the river canyon, and most sensors in SRC (with the exception of those located in side drainages) experienced westerly flow. These events tended to occur during 


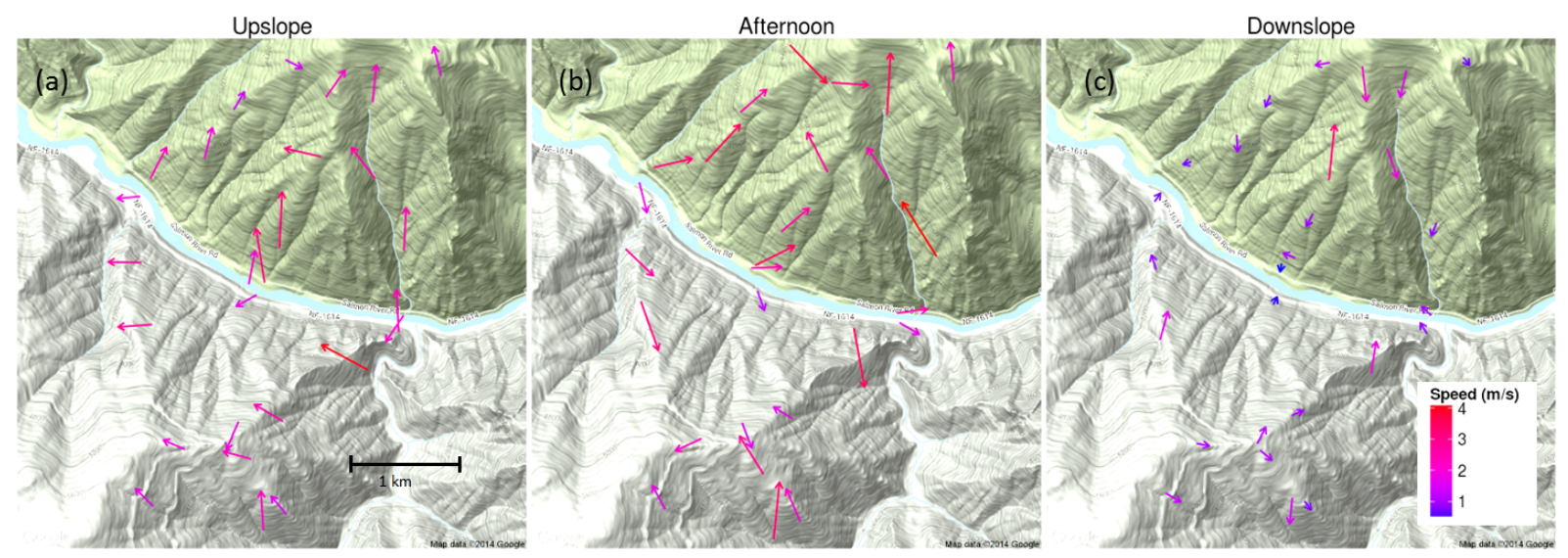

Figure 11. Average flows during (a) upslope (11:00 LT), (b) afternoon (16:00 LT), and (c) downslope (00:00 LT) regimes at the Salmon River Canyon site during periods of weak synoptic flow between July and September 2011. Vectors represent the average hourly flow at a given sensor. Periods of strong synoptic forcing were removed prior to averaging.

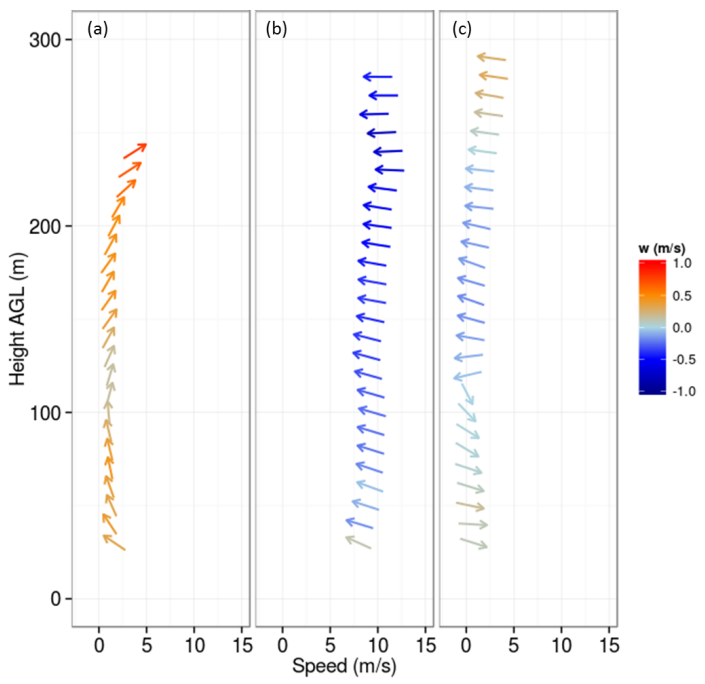

Figure 12. Vertical profiles measured at ST2 during (a) transition to downvalley flow (16 August 2011, 20:00 LT) and (b) synoptically driven downvalley flow (17 August 2011, 10:30 LT), and (c) transition to upvalley flow (18 August 2011, 09:30 LT).

mid-afternoon hours. Wind speeds during this type of synoptic disturbance ranged from 2.1 to $5.7 \mathrm{~m} \mathrm{~s}^{-1}$, with an average of $3.8 \mathrm{~m} \mathrm{~s}^{-1}$.

The highest observed wind speeds in the SRC were from the east during morning hours (Figs. 12, 13). Wind speeds during these pressure-driven downvalley events ranged from 0.84 to $9.1 \mathrm{~m} \mathrm{~s}^{-1}$, with an average of $3.1 \mathrm{~m} \mathrm{~s}^{-1}$. Figure $12 \mathrm{~b}$ shows a vertical profile of wind speeds measured at ST2 during one of these events. The profile data indicate a strong easterly flow with a negative w-component up to $280 \mathrm{~m}$ a.g.l. (Fig. 12b). These events occurred roughly every few days and appeared to be induced by a surface pressure gradient formed when a thermal trough existed on the
Columbia Plateau to the northwest of SRC, and high pressure existed to the east of SRC (Fig. 17). An east-west surface pressure gradient existed on days when enhanced downvalley flow was observed. On days when the downvalley flow feature was not observed, there was no east-west surface pressure gradient. The highest wind speeds during this type of flow event were observed at the upper elevations of the SRC (Fig. 18). The east-west surface pressure gradient coupled with the typical nighttime/early morning katabatic flow in the canyon resulted in very strong downvalley winds in the SRC. This pressure-enhanced katabatic surface flow tended to be decoupled from the larger-scale gradient flow (which is typically from the west) during these pressure-driven events.

\subsection{Archived data}

All data are archived and available to the public. Surface observations for each site are available as SQLite databases. Data from sodars, radar profilers, sonic anemometers, weather stations, and radiosondes are available in their raw formats. Access to these data along with tools to query, process, and visualize the data is described at https://collab. firelab.org/software/projects/wind-obs/repository. Descriptions of the NOAA mesonet data and contact information regarding mesonet data are found at http://www.noaa.inel.gov/ projects/INLMet/INLMet.htm.

\section{Conclusions}

We have presented an analysis of two high-resolution surface wind data sets, one collected from a tall isolated mountain, and the other from a steep river canyon. The wind data were analyzed and presented in terms of four flow regimes: upslope, afternoon, downslope, and a synoptically driven regime. These data sets constitute a unique inventory of surface wind measurements at very high spatial resolution under 

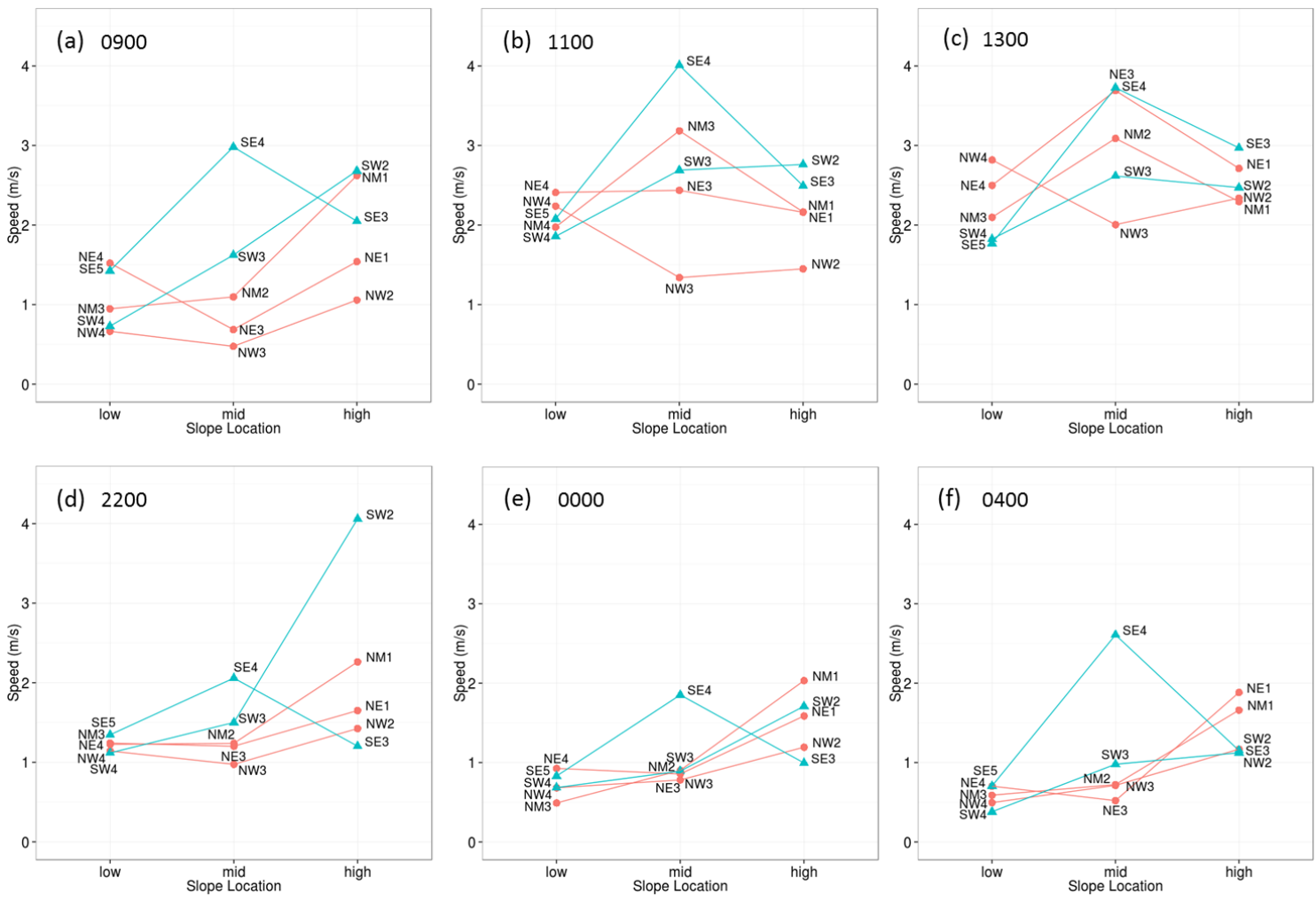

Figure 13. Average wind speeds for sensors at three slope locations (low, mid, and high) along five transects during $3 \mathrm{~h}$ of the upslope (a-c) and downslope (d-f) flow regimes at the Salmon River Canyon site. Blue and red lines are transects on the southern and northern sides of the river, respectively.

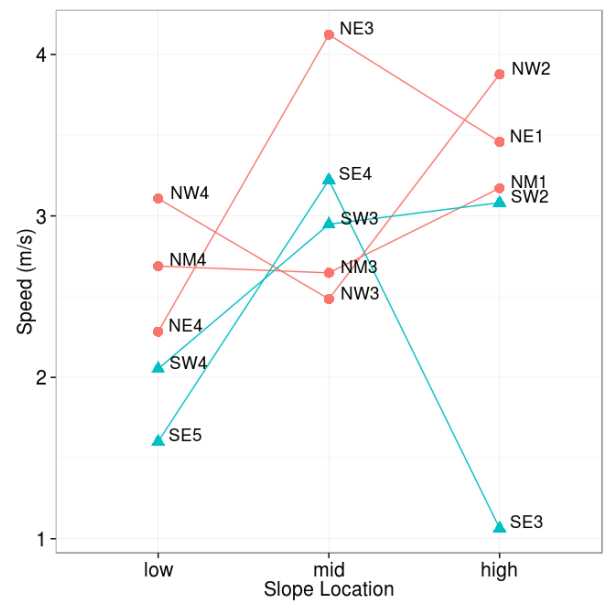

Figure 14. Average wind speeds for sensors at three slope locations (low, mid, and high) along five transects during the afternoon flow regime (17:00 LT) at the Salmon River Canyon site. Blue and red lines are transects on the southern and northern sides of the river, respectively.

dry summertime conditions. Public access to the archived data sets has been described.
Surface winds on and around BSB were completely decoupled from large-scale flows during upslope and downslope flow regimes, except for the highest-elevation ridgetop sensors. These ridgetop locations at BSB tended to correlate better with gradient-level winds than with the local diurnal surface flows. Surface winds in SRC were decoupled from large-scale flows except during periods of strong synoptic forcing that enhanced either upriver or downriver flows.

Wind speeds increased with distance upslope during the upslope regime at BSB, but generally decreased with distance upslope at SRC. Wind speed did not have a simple, consistent trend with position on the slope during the downslope regime at $\mathrm{BSB}$, but generally increased with distance upslope at SRC. We did not observe a convective mixing regime at SRC under periods of weak synoptic forcing, only a transition from upslope to thermally driven upriver flow.

The highest speeds measured at BSB occurred during the passage of frontal systems that generated strong southwesterly flows and during infrequent strong northwesterly flows presumably generated through SPCZ-like dynamics, thunderstorm outflows, or surface pressure gradients. Ridgetop winds were often twice as high as surface wind speeds measured on the surrounding SRP. The highest speeds measured at SRC occurred during late morning hours and were from easterly flows presumably produced by surface 

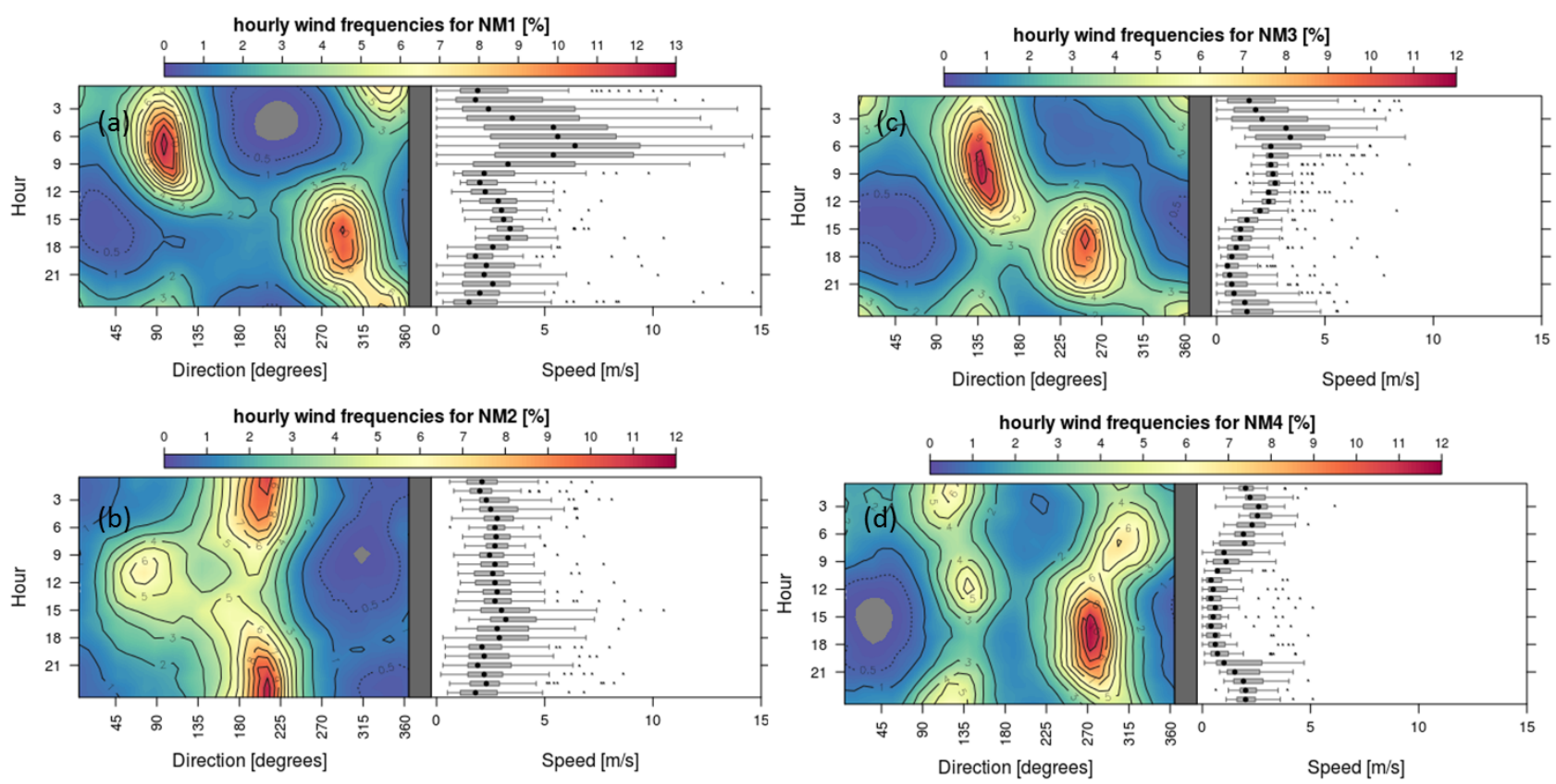

Figure 15. Contour plots of hourly wind frequencies and corresponding wind speeds for the NM transect at the Salmon River Canyon site. NM1 (a) is near the ridge top. NM4 (d) is near the canyon bottom. All data were used.

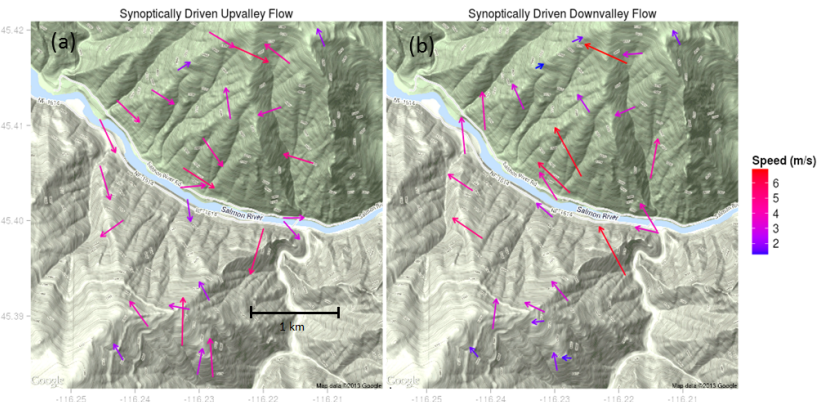

Figure 16. Characteristic (a) synoptically driven upvalley flow (15:00 LT) and (b) downvalley flow (11:00 LT) at the Salmon River Canyon site during July-September 2011. Vectors represent the average hourly flow at a given sensor. Periods of weak synoptic forcing were removed prior to averaging.

pressure gradients induced by formation of a thermal trough over the Columbia Plateau to the northwest and high pressure to the east. The highest wind speeds during these pressuredriven easterly flow events were measured at the mid- to high-elevation sensors.

These results have important implications for modeling near-surface winds in complex terrain. The fact that surface winds at both sites tended to be decoupled from large-scale flows under periods of weak synoptic forcing suggests that traditional operational weather model winds (i.e., with numerical grid resolutions of around $4 \mathrm{~km}$ or larger) are not likely to be good predictors of local winds in sub-grid scale complex terrain. Under periods of strong synoptic forcing,
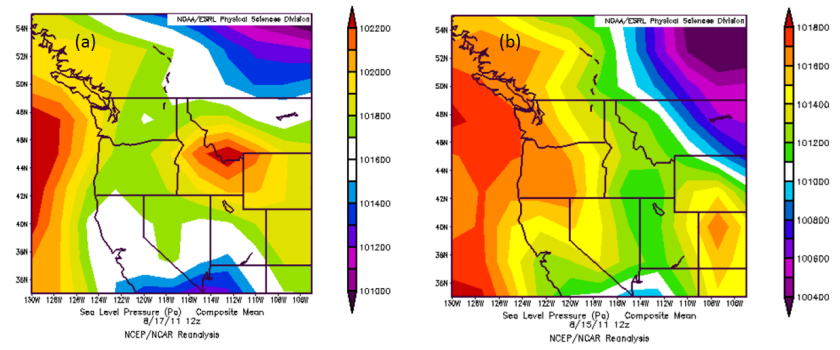

Figure 17. Synoptic-scale surface pressure conditions conducive to (a) enhanced easterly flow and (b) typical diurnal flow scenarios at the Salmon River Canyon site. North American Regional Reanalysis data courtesy of the National Center for Environmental Prediction.

variability in surface winds was sufficiently large due to terrain-induced mechanical effects (speed-up over ridges and decreased speeds on leeward sides of terrain obstacles) that a mean wind for a $4 \mathrm{~km}$ grid cell encompassing these terrain features would not be representative of actual surface winds at most locations on or within the terrain feature. The findings from this work along with the additional archived data and available mesonet data at BSB should provide guidance for future development and evaluation of high-resolution wind models and integrated parameterizations, such as for simulating diurnal slope flows and non-neutral atmospheric stability effects.

\section{The Supplement related to this article is available online} at doi:10.5194/acp-15-3785-2015-supplement. 

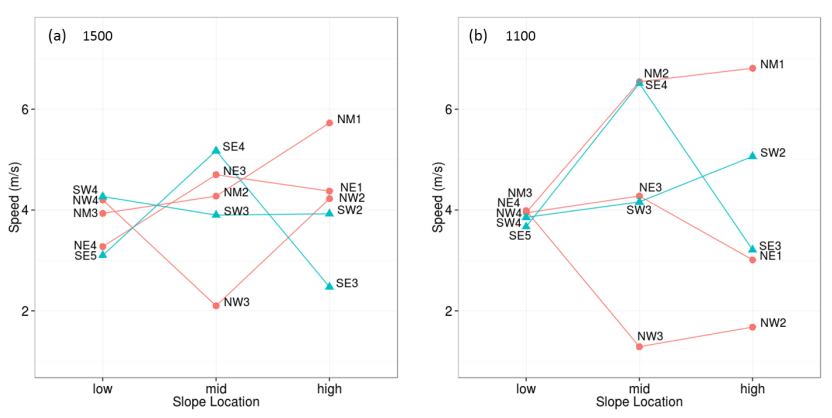

Figure 18. Average wind speeds for sensors at three slope locations (low, mid, and high) along five transects during the (a) synoptically driven upvalley and (b) synoptically driven downvalley flow regimes at the Salmon River Canyon site. Blue and red lines are transects on the southern and northern sides of the river, respectively.

Author contributions. B. Butler was principal investigator for the project, leading much of the field effort and developing a draft of the manuscript. All other authors participated in the data collection. $\mathrm{N}$. Wagenbrenner performed detailed data analysis and completed preparation of the manuscript with contributions from other authors corresponding to their order of authorship.

Acknowledgements. The Department of Interior Bureau of Land Management Idaho Falls, ID field office, facilitated the field campaign, and Barry Sorenson provided critical advice on local conditions, access roads, and weather as well as permission to store equipment on site during the deployment at Big Southern Butte. Thanks to Nicole Van Dyk, Olga Martyusheva, Jack Kautz, Peter Robichaud, and Ben Kopyscianski of the Rocky Mountain Research Station for help with the field installation and maintenance at the Salmon River site. Funding was provided by the Joint Fire Science Program, the US Forest Service, Washington State University, and the National Oceanic and Atmospheric Administration Field Research Division.

Edited by: T. Garrett

\section{References}

Andretta, T. A.: Climatology of the Snake River Plain convergence zone, National Weather Digest, 26, 37-51, 2002.

Andretta, T. Z. and Hazen, D. S.: Doppler radar analysis of a Snake River Plain convergence event, Weather Forecast., 13, 482-491, 1998.

Banta, R. M.: Daytime boundary-layer evolution over mountainous terrain, Part 1: observations of the dry circulations, Mon. Weather Rev., 112, 340-356, 1984.

Banta, R. M. and Cotton, R.: An analysis of the structure of local wind systems in a broad mountain basin, J. Appl. Meteorol., 20, 1255-1266, 1982.
Beaucage, P., Brower, M. C., and Tensen, J.: Evaluation of four numerical wind flow models for wind resource mapping, Wind Energy, 12, 197-208, doi:10.1002/we.1568, 2014.

Berg, J., Mann, J., Bechmann, A., Courtney, M. S., and Jørgensen, H. E.: The Bolund Experiment, Part I: Flow over a steep, three-dimensional hill, Bound.-Lay. Meteorol., 141, 219-243, 2011.

Chrust, M. F., Whiteman, C. D., and Hoch, S. W.: Observations of thermally driven wind jets at the exit of Weber Canyon, Utah, J. Appl. Meteorol. Climatol., 52, 1187-1200, 2013.

Daly, C., Conklin, D. R., and Unsworth, M. H.: Local atmospheric decoupling in complex topography alters climate change impacts, Int. J. Climatol., 30, 1857-1864, 2010.

Defant, F.: Zur Theorie der Hangwinde, nebst Bermekungen sur Theorie der Berg- und Talwinde, Archiv fuer Meteorologie Geophysik und Bioklimatologie, Ser. A., 1, 421-450, 1949.

Forthofer, J., Shannon, K., and Butler, B.: Simulating diurnally driven slope winds with WindNinja, Eighth Symposium on Fire and Forest Meteorology, Kalispell, MT, 13-15 October, 2009.

Forthofer, J. M., Butler, B. W., and Wagenbrenner, N. S.: A comparison of three approaches for simulating fine-scale surface winds in support of wildland fire management, Part I. Model formulation and comparison against measurements, Int. J. Wildland Fire, 23, 969-981, doi:10.1071/WF12089, 2014.

Geerts, B., Miao, Q., and Demko, J. C.: Pressure perturbations and upslope flow over a heated, isolated mountain, Mon. Weather Rev., 136, 4272-4288, 2008.

Grell, G. A., Emeis, S., Stockwell, W. R., Schoenemeyer, T., Forkel, R., Michalakes, J., Knoche, R., and Seidl, W.: Application of a multiscale, coupled MM5/chemistry model to the complex terrain of the VOTALP valley campaign, Atmos. Environ., 34, 1435-1453, 2000.

Horst, T. W. and Doran, J. C.: Nocturnal drainage flow on simple slopes, Bound.-Lay. Meteorol., 34, 263-286, 1986.

Jiménez, P. and Dudhia, J.: Improving the representation of resolved and unresolved topographic effects on surface wind in the WRF model. J. Appl. Meteorol. Climatol., 51, 300-316, 2012.

Jiménez, P., Jorba, O., Parra, R. and Baldasano, J. M.: Evaluation of MM5-EMICAT2000-CMAQ performance and sensitivity in complex terrain: high-resolution application to the northeastern Iberian peninsula, Atmos. Environ., 40, 5056-5072, 2006.

Kahle, D. and Wickham, H.: ggmap: a package for spatial visualization with Google Maps and OpenStreetMap. R package version 2.3, available at: http://CRAN.R-project.org/package= ggmap (last access: 30 March 2015), 2013.

Langhans, W., Juerg, S., Fuhrer, O., Bieri, S., and Schär, C.: Longterm simulations of thermally driven flows and orographic convection at convection-parameterizing and cloud-resolving resolutions. J. Appl. Meteorol. Climatol., 52, 1490-1510, 2013.

Lundquist, K. A., Chow, F. K., and Lundquist, J. K.: An immersed boundary method for the weather research and forecasting model, Mon. Weather Rev., 138, 796-817, 2010.

McNider, R. T. and Pielke, R. A.: Dirunal boundary-layer development over sloping terrain, J. Atmos. Sci., 38, 2198-2212, 1981.

Palma, J. M. L. M., Castro, F. A., Ribeiro, L. F., Rodrigues, A. H., and Pinto, A. P.: Linear and nonlinear models in wind resource assessment and wind turbine micro-siting in complex terrain, J. Wind Eng. Ind. Aerod., 96, 2308-2326, 2008. 
$\mathrm{R}$ Core Team: R: a language and environment for statistical computing, R Foundation for Statistical Computing, Vienna, Austria, available at: http://www.R-project.org/ (last access: 19 June 2014), 2013.

Reiter, E. R. and Tang, M.: Plateau effects on diurnal circulation patterns, Mon. Weather Rev., 112, 638-651, 1984.

Rothermel, R. C.: A Mathematical Model for Predicting Fire Spread in Wildland Fuels: Ogden, UT, USDA Forest Service, Research Paper INT-115, 40 pp., 1972.

Salabim, T.: Metvurst: meteorological visualization utilities using $\mathrm{R}$ for science and teaching, available at: https://github.com/ tim-salabim/metvurst, 2013.

Scire, J. S., Robe, F. R., Fernau, M. E., and Yamartino, R. J.: A User's Guide for the CALMET Meteorological Model, Earth Tech, Inc., Concord, MA, 2000.

Sharples, J. J., McRae, R. H. D., and Wilkes, S. R.: Wind-terrain effects on the propagation of wildfires in rugged terrain: fire channeling, Int. J. Wildland Fire, 21, 282-296, 2012.

Simpson, C. C., Sharles, J. J., Evans, J. P., and McCabe, M. F.: Large eddy simulation of atypical wildland fire spread on leeward slopes, Int. J. Wildland Fire, 22, 599-614, 2013.
Taylor, P. A. and Teunissen, H. W.: The Askervein Hill Project: overview and background data, Bound.-Lay. Meteorol., 39, 1539, 1987.

Wagenbrenner, N. S., Lamb., B. K., Forthofer, J. M., Shannon, K. S., and Butler, B. W.: Effect of model horizontal grid resolution on near-surface wind predictions in complex terrain: evaluations with high-resolution field observations from an isolated mountain and a steep river canyon, J. Appl. Meteorol. Climatol., in review, 2015

Whiteman, C. D.: Mountain Meteorology: Fundamentals and Applications, Oxford University Press. New York, 2000.

Zardi, D. and Whiteman, C. D.: Diurnal Mountain Wind Systems, in: Mountain Weather Research and Forecasting, edited by: Chow, F. K., De Wekker, S. F. J., and Snyder, B. J., 35-19, Springer Netherlands, Chap. 2, 2013.

Zhong, S. and Fast, J.: An evaluation of MM5, RAMS, and MesoEta models at subkilometer resolution using VTMX field campaign data in the Salt Lake valley, Mon. Weather Rev., 131, 1301-1322, 2003. 